\title{
Gate-keeper to coronary angiography: comparison of exercise testing, myocardial perfusion SPECT and individually tailored approach for risk stratification
}

\author{
Stefano Muzzarelli • Matthias Emil Pfisterer • \\ Jan Müller-Brand • Michael Johannes Zellweger
}

Received: 22 November 2009/Accepted: 26 March 2010/Published online: 22 April 2010

(C) Springer Science+Business Media, B.V. 2010

\begin{abstract}
We aimed to evaluate the differences between exercise testing (ET), myocardial perfusion SPECT (MPS) and a combination of ET and MPS based risk assessment as outlined by the guidelines with respect to their "gate-keeper" role to coronary angiography (cath) and the associated diagnostic procedural costs if prognostic considerations, as those proposed by the current guidelines and the recent literature, were taken into account. The Duke-score and the summed difference score (SDS; extent of ischemia) were assessed in 955 consecutive patients referred for MPS combined with ET. According to the guidelines and the available literature, three different algorithms for risk stratification were retrospectively applied: (1) ET based risk stratification and cath if intermediate or high risk Duke-score; (2) MPS based risk stratification and cath if SDS $\geq 8$; (3) combined approach with ET as first step and MPS in
\end{abstract}

S. Muzzarelli · M. E. Pfisterer · M. J. Zellweger ( $₫)$ Cardiology Department, University Hospital Basel, Petersgraben 4, 4031 Basel, Switzerland

e-mail: zellwegerm@uhbs.ch

\section{S. Muzzarelli}

Radiology Department, Cardiac and Pulmonary Imaging, University of California, San Francisco, USA

J. Müller-Brand

Nuclear Medicine Department, University Hospital Basel, Basel, Switzerland case of intermediate risk Duke-score. A cath would have been suggested in every patient with either high risk Duke-score or SDS $\geq 8$ in patients with intermediate risk Duke-score. The referral rate to cath was $27 \%$ according to the ET alone, $13 \%$ using MPS, and finally $12 \%$ applying the combined risk stratification. The cost of the diagnostic work-up including cath were: $615 €, 1$ '299€, and $598 €$ per patient, respectively. The coronary angiography referral rate widely depends on the diagnostic modality used for risk stratification and according to the referral criteria provided by the guidelines. In the present study, the use of a stress imaging modality (MPS) and published prognostic data was associated with a lower referral rate to cath as compared to exercise testing alone and thus underlines the advantage of a risk based approach applying stress imaging in patients with intermediate risk Duke-score.

Keywords Coronary artery disease .

Myocardial perfusion SPECT - Exercise testing ·

Duke-score · Coronary angiography ·

Cost effectiveness

\section{Introduction}

Exercise testing and myocardial perfusion SPECT (MPS) are well established for the diagnostic and 
prognostic assessment of patients with suspected or known coronary artery disease (CAD). The results of both non-invasive diagnostic modalities help to guide the therapeutic approach and identify candidates for coronary angiography among patients with stable CAD. According to the American College of Cardiology/American Heart Association (ACC/AHA) guidelines, patients with stable CAD stratified to low risk after exercise testing can be managed medically without need of coronary angiography and patients at high risk should be referred for coronary angiography. For patients with intermediate risk according to exercise testing, the guidelines suggest either a coronary angiography or an exercise imaging test [1]. Even if MPS is considered superior to exercise testing for risk stratification of patients with $\mathrm{CAD}$, to date there is no direct comparison between these diagnostic modalities with respect to the their "gate-keeper" role for coronary angiography if indications as outlined by the available guidelines and the prognostic literature are applied [2-6]. In this context, and considering that the guidelines advise either direct coronary angiography or supplementary imaging based risk stratification for patients with intermediate risk Duke-score, we aimed to compare the hypothetical referral rate to coronary angiography based on three different risk stratification algorithms: (a) risk stratification based on exercise testing alone, (b) risk stratification based on MPS alone, and (c) risk stratification based on combined diagnostic modalities with exercise testing as first line assessment and subsequent MPS for patients with intermediate risk according to exercise testing. Furthermore we aimed to compare the costs of the above described diagnostic approaches.

\section{Materials and methods}

\section{Patient population}

Consecutive patients referred for MPS for CAD evaluation $(n=1,132)$ who were able to undergo exercise stress (bicycle ergometry) were included in this analysis. Patients with ST-segment depression $\geq 1 \mathrm{~mm}$ or left bundle branch block on their baseline electrocardiogram were excluded $(n=177)$. Detailed medical history has been collected in all patients. Whenever possible, beta-blocking medications as well as negative chronotropic calcium antagonists were withheld for $48 \mathrm{~h}$ and long-acting nitrates for $24 \mathrm{~h}$ before exercise testing.

\section{Exercise testing}

Resting heart rate, blood pressure and 12-lead ECG were recorded before exercise. A standardized, stepwise and symptom limited bicycle exercise test was performed in all subjects to the end points as defined in the exercise testing guidelines [7]. A 12-lead ECG was continuously recorded during exercise and recovery. Blood pressure was recorded every minute during exercise and recovery. ST-segment deviation was assessed automatically (CARDIOVIT CS-200 ${ }^{\circledR}$, Schiller) and visually controlled and interpreted by an experienced cardiologist, who was blinded for the MPS results. Maximum ST-segment depression (STD in $\mathrm{mm}, 1 \mathrm{~mm}=0.1 \mathrm{mV}$ ) was defined as the maximal exercise-induced ST-segment depression $80 \mathrm{~ms}$ after the $\mathrm{J}$ point, which was horizontal or downsloping; it was calculated by subtracting the maximum ST-segment deviation during exercise or post exercise from the resting ST-segment level in the corresponding lead. Maximum STD was considered ischemic if $\geq 1 \mathrm{~mm}$. Exercise testing was considered positive in case of typical exercise induced angina or significant STD (horizontal or downsloping and $\geq 1 \mathrm{~mm}$ ). The workload was expressed in metabolic equivalents (METs). Based on the exercise testing variables a modified Duke-score for bicycle ergometry was calculated using the following definition: (exercise capacity in METs $-[5 \times$ maximum ST-segment depression in $\mathrm{mm}]-[4 \times$ angina index $])$ with angina index defined as a value of 0 if no angina occurred, 1 if typical non-test limiting angina, and 2 if test limiting angina occurred $[8,9]$. According to previous published data and to the ACC/AHA guidelines for patients with chronic stable angina, patients were stratified in a low risk group if the Duke-score was $\geq 5$, intermediate between -10 and 4 , and a high risk $\leq-11[1,9]$.

\section{Myocardial perfusion imaging}

All patients underwent routine rest/stress (ergometry) dual isotope (Tl-201 rest/Tc-99 m sestamibi) MPS protocol as previously described [10, 11]. Rest-SPECT was obtained after administration of $111 \mathrm{MBq}$ Tl-201. Tl-201 SPECT was performed $10 \mathrm{~min}$ after tracer 
injection. At near-maximal exercise, a $740 \mathrm{MBq}$ dose of Tc-99 m sestamibi was injected and exercise was continued for at least an additional minute after injection. Post-stress gated SPECT was acquired in average 95-100 min post-stress. SPECT imaging was performed following standard protocols. No attenuation or scatter correction was used. SPECT images were acquired and processed as previously described, with a circular $180^{\circ}$ acquisition. During imaging, two energy windows were used for Tl-201, including a $30 \%$ window centered on the $70-\mathrm{keV}$ peak and a $20 \%$ window centered on the $167-\mathrm{keV}$ peak. For Tc-99 m sestamibi SPECT, a $15 \%$ window centered on the 140$\mathrm{keV}$ peak was used.

Semiquantitative visual interpretation was performed using a 20-segment model. Each segment was scored using a five-point scoring system: $0=$ normal, $1=$ equivocal, $2=$ moderate, $3=$ severe reduction of radioisotope uptake, and $4=$ apparent absence of detectable tracer uptake in a segment. A summed stress score (SSS) was calculated by adding the scores of the 20 segments of the stress images, and a summed rest score (SRS) by adding the scores of the 20 segments of the rest images. To assess defect reversibility, a summed difference score (SDS) was calculated by subtracting SRS from SSS, reflecting the severity and extent of ischemia. MPS was considered abnormal in case of scar (SRS $\geq 4$ ) or ischemia ( $\operatorname{SDS} \geq 2$ ). Moderate to severe ischemia was defined as an SDS $\geq 8$.

Risk stratification according to exercise test, myocardial perfusion SPECT and combined approach. Study algorithm for referral to coronary angiography

According to the available literature and to the guidelines three different algorithms were defined based on prognostic information derived from the exercise test and MPS to refer patients for coronary angiography (see Table 1) [1, 12-16]. Each of the described algorithms for risk stratification has been retrospectively applied to all 955 patients to assess the hypothetical referral rate to coronary angiography.

\section{Cost analysis}

The costs generated by the different diagnostic procedures were calculated based on the official
Swiss medical system TARMED. The cost estimates were as follows: coronary angiography $1810 €$, myocardial perfusion SPECT $1060 €$ and exercise test $130 €$. The cost per patient generated by the exercise test based risk stratification was calculated adding the cost of the exercise tests for all patients and the cost of the coronary angiography for patients with intermediate to high risk exercise test results divided by the total number of patients included in the present analysis. In analogy, the cost per patient generated by MPS based risk stratification was calculated adding the cost of an MPS for all patients and the cost of coronary angiography for patients with a SDS $\geq 8$ divided by the total number of patients. Finally, the cost per patient generated by the combined approach for risk stratification was calculated by summing up the cost of the exercise test for all patients, the cost of the MPS for patients with intermediate Duke-score and the cost of the coronary angiography for patients who qualified for a further invasive diagnostic procedure as described in the methods, divided by the total number of patients.

\section{Statistics}

Numerical data are presented as mean \pm SD. Categorical data are presented as numbers and percentages. The different hypothetical referral rates to coronary angiography of the exercise testing, MPS and the combined approach were compared with a Chi-square test. Univariate predictors for discrepant findings between exercise testing and MPS results with respect to risk stratification were tested by Fisher's test for nominal variables, Students $t$-test for numerical variables with equal distribution and Mann-Whitney test for numerical variables with non-equally distribution. Independent predictors of discrepant findings of exercise testing and MPS results with respect to risk stratification were identified including the univariate significant variables $(P \leq 0.05)$ in a multivariable logistic regression. The differences between the diagnostic procedural costs of the different strategies for risk assessment were compared by the Wilcoxon test. A $P$-value of $\leq 0.05$ was considered statistically significant. Analyses were performed using the commercially available statistical package SPSS version 15.0. 
Table 1 Prognostic criteria for referral to coronary angiography according to the 3 different diagnostic and risk stratification approaches

\begin{tabular}{lll}
\hline Exercise testing & MPS & Combination of exercise testing and MPS \\
\hline Positive ET with intermediate to high risk Duke-score & SDS $\geq 8$ & $\begin{array}{l}\text { Positive ET and high risk Duke-score } \\
\text { Positive ET, intermediate risk Duke-score and SDS } \geq 8\end{array}$ \\
\hline
\end{tabular}

ET exercise testing, SDS summed difference score

\section{Results}

Patient characteristics

Patient characteristics are summarized in Table 2. The mean age of the 955 patients was almost 61 years and the majority were male $(70 \%)$. Approximately half of the patients had a history of prior CAD.

Results of stress ECG and myocardial perfusion SPECT

As shown in Table 3, the majority of patients achieved the submaximal predicted heart rate and the maximal double product (peak heart rate $\mathrm{x}$ maximal systolic blood pressure) was consistent with an adequate stress test. Stress ECG was positive in 266 patients (28\%). Among those, 10 patients (4\%) had a low risk, $230(86 \%)$ had an intermediate risk and $26(10 \%)$ had a high risk.

Myocardial perfusion SPECT was considered abnormal in almost half of the patients (scar, ischemia, or both). Among patients with evidence of ischemia ( $n=367,38 \%) 126$ (13\% of the entire collective) had a SDS $\geq 8$, consistent with a prognostic high risk ischemia, likely to benefit from revascularization (Table 4).

Impact of the different algorithms for risk stratification on referral to coronary angiography and procedural costs

As depicted in Table 5, applying the exercise testing based algorithm for risk stratification, 256 patients (27\%) would have been referred to coronary angiography because of a positive exercise test and a Dukescore $<5$. Using MPS as a first line and only diagnostic modality for risk stratification, 126 patients $(13 \%)$ would have been referred to coronary
Table 2 Baseline characteristics

\begin{tabular}{|c|c|}
\hline & Overall $(n=955)$ \\
\hline Male gender $(\%)$ & $666(70)$ \\
\hline Age (years \pm SD) & $61 \pm 11$ \\
\hline BMI $\left(\mathrm{kg} / \mathrm{m}^{2} \pm \mathrm{SD}\right)$ & $27.5 \pm 4.6$ \\
\hline Known CAD (\%) & $409(43)$ \\
\hline Prior MI (\%) & $249(26)$ \\
\hline Prior revascularization (\%) & $377(40)$ \\
\hline \multicolumn{2}{|l|}{ Symptoms } \\
\hline Typical angina (\%) & $219(23)$ \\
\hline Atypical angina (\%) & $304(32)$ \\
\hline Dyspnoea (\%) & $321(34)$ \\
\hline \multicolumn{2}{|l|}{ Risk factors } \\
\hline Diabetes $(\%)$ & $222(23)$ \\
\hline Hypercholesterolemia (\%) & $559(59)$ \\
\hline Hypertension (\%) & $605(63)$ \\
\hline Family history (\%) & $303(32)$ \\
\hline Smoking (\%) & $424(44)$ \\
\hline \multicolumn{2}{|l|}{ Medication } \\
\hline Aspirin (\%) & $653(68)$ \\
\hline$\beta$-blockers $(\%)$ & $540(57)$ \\
\hline Nitrates $(\%)$ & $66(7)$ \\
\hline Ca-antagonist (\%) & $154(16)$ \\
\hline ACE-inhibitors (\%) & $226(24)$ \\
\hline ATII-antagonist (\%) & $219(23)$ \\
\hline Statins $(\%)$ & $522(55)$ \\
\hline
\end{tabular}

$B M I$ body mass index, $C A D$ coronary artery disease, $M I$ myocardial infarction, $A C E$ angiotensin converting enzyme, ATII angiotensin II

angiography because of SDS $\geq 8$. Finally, applying the algorithm with exercise testing as first tool for risk stratification with subsequent MPS in case of intermediate risk exercise testing 112 patients (12\%) would have been referred to coronary angiography; 26 because of a high risk Duke-score and 86 because of an intermediate risk Duke-score with $\mathrm{SDS} \geq 8$. The cost per patient of the diagnostic procedure generated by the three different algorithms were: $615 €, 1 ' 299 €$, 
Table 3 Exercise testing variables

\begin{tabular}{ll}
\hline & Overall $(n=955)$ \\
\hline Heart rate & \\
Resting HR $(\mathrm{bpm} \pm \mathrm{SD})$ & $80 \pm 15$ \\
Peak HR (bpm $\pm \mathrm{SD})$ & $148 \pm 16$ \\
Blood pressure & $129 \pm 24$ \\
Resting SBP $(\mathrm{mmHg} \pm \mathrm{SD})$ & $213 \pm 35$ \\
Peak SBP (mmHg \pm SD) & $81 \pm 13$ \\
Resting DBP (mmHg $\pm \mathrm{SD})$ & $79 \pm 21$ \\
Peak DBP (mmHg \pm SD) & $7.2 \pm 1.8$ \\
Maximal workload (METs \pm SD) & $6 \pm 1$ \\
Exercise test duration (minutes \pm SD) & $908(95)$ \\
Submaximal predicted HR achieved $(\%)$ & $31,590 \pm 6,417$ \\
Double product reached $( \pm \mathrm{SD})$ & $126(13)$ \\
Typical angina during exercise $(\%)$ & $215(22)$ \\
STD $\geq 1$ mm $(\%)$ & $266(28)$ \\
Positive stress ECG $(\%)$ &
\end{tabular}

$H R$ heart rate, $b p m$ beats pro minute, $S B P$ systolic blood pressure, $D B P$ diastolic blood pressure, $M E T$ metabolic equivalent, $S T D$ maximal ST-segment depression

Table 4 Results of the myocardial perfusion SPECT

\begin{tabular}{lc}
\hline & Overall $(n=955)$ \\
\hline Scar: SRS $\geq 4(\%)$ & $274(29)$ \\
Ischemia: SDS $\geq 2(\%)$ & $367(38)$ \\
Severe ischemia: SDS $\geq 8(\%)$ & $126(13)$ \\
Abnormal MPS (\%) & $453(47)$ \\
SRS (median, IQR) & $0(0-4)$ \\
SSS (median, IQR) & $2(0-9)$ \\
SDS (median, IQR) & $0(0-4)$ \\
\hline
\end{tabular}

SRS summed rest score, SDS summed difference score, MPS myocardial perfusion SPECT, abnormal MPS MPS consistent with scar or ischemia, $I Q R$ interquartile range

and $598 €$ for exercise testing only, MPS, and the combined approach, respectively (Table 5).

In a subgroup analysis, patients without history of CAD were evaluated $(n=546,57 \%)$. Of these, 124 (23\%) had a positive exercise test and $116(21 \%)$ would have been referred to coronary angiography according to the exercise testing based risk stratification (Duke-score $<5$ ). Myocardial perfusion SPECT was abnormal in 153 patients (28\%), 132 (24\%) had myocardial ischemia (SDS $\geq 2$ ) and 58 patients $(11 \%)$ would have been referred to coronary angiography based on the MPS risk stratification
(SDS $\geq 8$ ). Finally, applying the combined diagnostic approach for risk stratification, 56 (10\%) patients would have been referred to coronary angiography; 15 because of a high risk exercise test and 41 because of an intermediate risk exercise test with $\mathrm{SDS} \geq 8$ (Table 5).

Correlation between exercise testing and myocardial perfusion results

The correlation between Duke-score and extent of ischemia is shown in Fig. 1. As illustrated, the proportion of patients with greater extent of ischemia increased as a function of the Duke-score ( $P$-for trend $<0.01)$. Of note, among the $699(73 \%)$ patients with negative exercise test or positive exercise test but low risk Duke-score only 18 patients $(2.6 \%)$ and $1.8 \%$ of the entire collective had a SDS $\geq 8$. Among patients with a positive exercise test and intermediate risk Duke-score $38 \%$ had a SDS $\geq 8$. And finally, among patients with high risk Duke-score $81 \%$ had a SDS $\geq 8$ (see Fig. 1).

In a univariate analysis, patients with intermediate or high risk based on exercise testing but SDS $<8$ on MPS (58\%) more often were female (22 vs. $13 \%$; $P=0.04), \quad$ were younger $\quad(62.4 \pm 9.2 \quad$ vs. $65.0 \pm 10.5$ years; $P=0.05)$, more often had stopped beta-blockers before exercise testing (60 vs. 42\%; $P<0.01)$, had achieved a higher peak heart rate during exercise ( $147 \pm 15$ vs. $140 \pm 17$ beat/ minute; $P<0.01$ ) and were less likely to have a history of typical angina (38 vs. $60 \% ; P<0.01$ ). In the multivariate regression analysis, female sex $(95 \%$ CI: $1.1-4.3 ; P=0.04)$, discontinuation of betablockers before exercise testing (95\% CI: 1.2-3.5; $P<0.01)$, as well as absence of typical angina $(95 \%$ CI: $1.5-4.3 ; P<0.01)$ were independent predictors of SDS $<8$ despite of a Duke-score $<5$.

\section{Discussion}

To our knowledge this study is the first one evaluating different diagnostic CAD algorithms based on the most recent risk stratification data and comparing the costs of these different approaches $[12,17]$. The present study suggests that the risk stratification of patients evaluated for known or suspected CAD may substantially differ depending on the diagnostic 
Table 5 Referral rates to coronary angiography and procedural costs associated with the different diagnostic and risk stratification approaches

\begin{tabular}{|c|c|c|c|c|c|}
\hline All patients $(n=955)$ & ET & MPS & $P$-value* & ET and MPS & $P$-value** \\
\hline Patients referred to coronary angiography $(\%)$ & $256(27)$ & $126(13)$ & $<0.01$ & $112(12)$ & $<0.01$ \\
\hline Costs of the diagnostic procedure (per patient, $€$ ) & 615 & 1299 & $<0.01$ & 598 & 0.02 \\
\hline \multicolumn{6}{|l|}{ Patients without known CAD $(n=546)$} \\
\hline Patients referred to coronary angiography (\%) & $116(21)$ & $58(11)$ & $<0.01$ & $56(10)$ & $<0.01$ \\
\hline Costs of the diagnostic procedure (per patient, $€$ ) & 515 & 1252 & $<0.01$ & 512 & 0.08 \\
\hline
\end{tabular}

$E T$ exercise test, $M P S$ myocardial perfusion SPECT, $€$ Euro, $P$-value* comparison between MPS and ET, $P$-value** comparison between combination of ET/MPS and ET alone

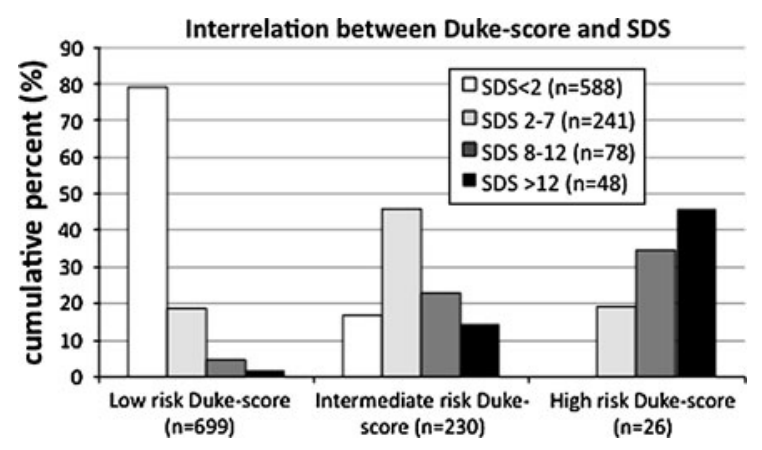

Fig. 1 Interrelation between Duke-score and SDS categories ( $P$-for trend $<0.01)$. Note the relevant proportion of patients with moderate to severe ischemia among patients with high risk Duke-score and the low percentage of patients with moderate to severe ischemia among patients with low risk Duke-score

modality used for risk stratification. In this context, MPS based risk stratification, as well as the combined approach with exercise testing as first approach and MPS in case of intermediate risk, may have both a stronger "gate-keeper" role with respect to referral to coronary angiography as compared to exercise testing alone if prognostic considerations of current guidelines and the recent literature are taken into account. Based on the proposed prognostic decisional algorithm, the number of coronary angiographies would have been reduced by more than $50 \%$ using MPS or the combined approach for risk stratification. Notably, the lower coronary angiography referral rate was similar in patients with and without history of CAD. Of note, the total costs of the diagnostic procedure were substantially higher if MPS was used in all patients as a first line modality for risk stratification. On the other hand, the combined approach with stress imaging applied only in selected patients with intermediate risk during exercise testing demonstrated a very low risk of misclassification (meaning that only a minority of patients with low risk Duke-score had a relevant myocardial ischemia), and a good cost performance if only costs related to the diagnostic work-up are considered.

There is plenty of evidence, that imaging modalities, as MPS, provide incremental prognostic value with respect to prediction of major cardiovascular events as compared to exercise testing alone. These findings have been confirmed by several studies and in different subsets of patients evaluated for known or suspected CAD [2-6]. Even though, the different impact of imaging based risk stratification as compared to exercise testing with respect to clinical decision making and referral to subsequent coronary angiography has not been analyzed by all of the above mentioned studies.

The prognostic benefit of revascularization procedures in patients with stable CAD has been questioned by several recent randomized trials [18-23]. The recently published COURAGE and BARI 2D studies showed that percutaneous coronary intervention in addition to optimal medical treatment was not superior to medical therapy alone in terms of prognosis and quality of life [18, 19, 24]. Of note, a documented ischemia was an inclusion criterion of the COURAGE trial, but no minimal threshold of myocardium ischemic was taken into account for inclusion and patients with severe ischemia were excluded [18]. This aspect is of particular importance considering that the benefit of a revascularization procedure may be dependent on the extent of ischemic myocardium. A study reported by Hachamovitch et al. suggested that myocardial revascularization compared to medical therapy had greater survival benefit only in patients with moderate to large amount of inducible ischemia ( $>10 \%$ myocardium ischemic) [12]. This seems to hold true also 
for asymptomatic patients [14]. Similarly, the nuclear substudy of the COURAGE trial indicates that patients with moderate to severe pre-treatment ischemia had a worse prognosis and were more likely to benefit from revascularization in terms of reduction of myocardium ischemic and increased event free survival as compared to patients with less severe ischemia [13]. In this context, the value of non-invasive risk stratification for patients with stable CAD seems to be of outstanding importance, in order to select and identify low risk patients, who can safely be treated medically without further testing and on the other hand high risk patients, who may benefit from angiography and potential revascularization [25].

The present study provides the evidence that patients' allocation to a specific risk category may widely differ according to the diagnostic modality used for risk assessment. As a consequence, performing risk stratification with MPS or combination of exercise testing and MPS on an individual basis result in less patients being referred to coronary angiography as compared to exercise testing alone. Additionally, the costs of the diagnostic procedure were almost the same if exercise testing alone or the more "sophisticated" combined risk stratification approach was used. This was due to the reduced number of coronary angiographies in the combined scenario. Therefore, the present study underlines possible advantages of a combined approach with stress imaging applied in patients with an intermediate risk exercise test even applying prognostic considerations. Of note, also considering the results of risk stratification the proportion of patients with high risk MPS results was very low (2.6\%) among patients with a Duke-score indicating a low risk and on the other hand high $(81 \%)$ among patients with a high risk Duke-score. Therefore, among patients stratified to low or high risk according to the exercise testing alone, there was a good concordance between exercise testing and MPS with respect to the hypothetical treatment allocation (medically vs. coronary angiography). In contrast, among patients with intermediate Duke-score a great proportion of patients $(62 \%)$ did not meet high-risk criteria on MPS. Patients of female gender, as well as patients who discontinued betablocking medications before exercise testing or patients without typical angina were particularly prone to have discordant results with respect to risk stratification between exercise testing and MPS, meaning low risk MPS findings despite of intermediate to high risk exercise testing. Keeping in mind, that MPS is superior to exercise testing for risk stratification, the present results suggest that further risk stratification based on MPS in patients with an intermediate exercise testing Duke-score may be favorable, in order to reduce the referral rate to coronary angiography if strictly prognostic considerations, as those proposed by the current guidelines and the recent literature, are taken into account. Still, this study is not intended to provide any definitive advice regarding procedure for risk stratification of patients evaluated for $\mathrm{CAD}$, but may point to the relevant differences in risk stratification depending of the diagnostic modality used.

\section{Limitations}

The study is an observational study, no randomized allocation to different diagnostic procedures for risk stratification was performed and no follow-up data were available. The accepted gold standard of coronary angiography can't be provided in this study. Coronary angiography is superior to MPS to establish the diagnosis of CAD, even though, the combination of clinical data and myocardial perfusion data has been shown to be superior than the combination of clinical data and coronary angiography data for prognostic purposes [26]. Indeed, even when angiographic CAD is present, MPS is a powerful method for risk stratification. In this context, as the proposed decisional algorithm is based strictly on prognostic consideration, the absence of the angiographic data should not compromise the conclusion of the present study. Of course, this data only applies to patients who are able to undergo an adequate ergometry test (i.e. this data can't be used for pharmacologically stressed patients).

\section{Conclusion}

The patients' allocation to specific risk categories and the referral rate to coronary angiography may be widely different depending on the diagnostic modality used for risk stratification as outlined by the guidelines. In the present study population, the use of a stress imaging modality as MPS was associated with a lower referral rate to coronary angiography as 
compared to exercise testing alone if prognostic information, as those proposed by the current guidelines and the recent literature, were considered. The present study indicates possible advantages of a combined approach with individually tailored use of stress imaging in patients with intermediate risk exercise tests due to a very low risk of a prognostic misclassifications for patients with low Duke-score (meaning that only a minority of patients with low risk Duke-score had a relevant myocardial ischemia), and to its good cost performance.

Acknowledgments This study was done without financial supports.

Conflict of interest None of the authors has conflicts of interest.

\section{References}

1. Gibbons RJ, Chatterjee K, Daley J, Douglas JS, Fihn SD, Gardin JM, Grunwald MA, Levy D, Lytle BW, O’Rourke RA, Schafer WP, Williams SV, Ritchie JL, Cheitlin MD, Eagle KA, Gardner TJ, Garson AJ, Russell RO, Ryan TJ, Smith SCJ (1999) ACC/AHA/ACP-ASIM guidelines for the management of patients with chronic stable angina: a report of the American College of Cardiology/American Heart Association Task Force on Practice Guidelines (Committee on Management of Patients With Chronic Stable Angina). J Am Coll Cardiol 33:2092-2197

2. Berman DS, Hachamovitch R, Kiat H, Cohen I, Cabico JA, Wang FP, Friedman JD, Germano G, Van Train K, Diamond GA (1995) Incremental value of prognostic testing in patients with known or suspected ischemic heart disease: a basis for optimal utilization of exercise technetium-99 m sestamibi myocardial perfusion single-photon emission computed tomography. J Am Coll Cardiol 26:639-647

3. De Lorenzo A, Hachamovitch R, Kang X, Gransar H, Sciammarella MG, Hayes SW, Friedman JD, Cohen I, Germano G, Berman DS (2005) Prognostic value of myocardial perfusion SPECT versus exercise electrocardiography in patients with ST-segment depression on resting electrocardiography. J Nucl Cardiol 12:655-661

4. Hachamovitch R, Berman DS, Kiat H, Cohen I, Friedman JD, Shaw LJ (2002) Value of stress myocardial perfusion single photon emission computed tomography in patients with normal resting electrocardiograms: an evaluation of incremental prognostic value and cost-effectiveness. Circulation 105:823-829

5. Hachamovitch R, Berman DS, Shaw LJ, Kiat H, Cohen I, Cabico JA, Friedman J, Diamond GA (1998) Incremental prognostic value of myocardial perfusion single photon emission computed tomography for the prediction of cardiac death: differential stratification for risk of cardiac death and myocardial infarction. Circulation 97:535-543
6. Valeti US, Miller TD, Hodge DO, Gibbons RJ (2005) Exercise single-photon emission computed tomography provides effective risk stratification of elderly men and elderly women. Circulation 111:1771-1776

7. Gibbons RJ, Balady GJ, Bricker JT, Chaitman BR, Fletcher GF, Froelicher VF, Mark DB, McCallister BD, Mooss AN, O'Reilly MG, Winters WL, Gibbons RJ, Antman EM, Alpert JS, Faxon DP, Fuster V, Gregoratos G, Hiratzka LF, Jacobs AK, Russell RO, Smith SC (2002) ACC/AHA 2002 guideline update for exercise testing: summary article. A report of the American College of Cardiology/American Heart Association Task Force on Practice Guidelines (Committee to Update the 1997 Exercise Testing Guidelines). J Am Coll Cardiol 40:1531-1540

8. Kligfield P, Lauer MS (2006) Exercise electrocardiogram testing: beyond the ST segment. Circulation 114:20702082

9. Mark DB, Hlatky MA, Harrell FEJ, Lee KL, Califf RM, Pryor DB (1987) Exercise treadmill score for predicting prognosis in coronary artery disease. Ann Intern Med 106:793-800

10. Berman DS, Kiat H, Friedman JD, Wang FP, van Train K, Matzer L, Maddahi J, Germano G (1993) Separate acquisition rest thallium-201/stress technetium-99 m sestamibi dual-isotope myocardial perfusion single-photon emission computed tomography: a clinical validation study. J Am Coll Cardiol 22:1455-1464

11. Zellweger MJ, Kaiser C, Brunner-La Rocca HP, Buser PT, Osswald S, Weiss P, Mueller-Brand J, Pfisterer ME (2008) Value and limitations of target-vessel ischemia in predicting late clinical events after drug-eluting stent implantation. J Nucl Med 49:550-556

12. Hachamovitch R, Hayes SW, Friedman JD, Cohen I, Berman DS (2003) Comparison of the short-term survival benefit associated with revascularization compared with medical therapy in patients with no prior coronary artery disease undergoing stress myocardial perfusion single photon emission computed tomography. Circulation 107:2900-2907

13. Shaw LJ, Berman DS, Maron DJ, Mancini GB, Hayes SW, Hartigan PM, Weintraub WS, O'Rourke RA, Dada M, Spertus JA, Chaitman BR, Friedman J, Slomka P, Heller GV, Germano G, Gosselin G, Berger P, Kostuk WJ, Schwartz RG, Knudtson M, Veledar E, Bates ER, McCallister B, Teo KK, Boden WE (2008) Optimal medical therapy with or without percutaneous coronary intervention to reduce ischemic burden: results from the clinical outcomes utilizing revascularization and aggressive drug evaluation (COURAGE) trial nuclear substudy. Circulation 117:1283-1291

14. Zellweger MJ, Hachamovitch R, Kang X, Hayes SW, Friedman JD, Germano G, Berman DS (2009) Threshold, incidence, and predictors of prognostically high-risk silent ischemia in asymptomatic patients without prior diagnosis of coronary artery disease. J Nucl Cardiol 16:193-200

15. Zellweger MJ, Hachamovitch R, Kang X, Hayes SW, Friedman JD, Germano G, Pfisterer ME, Berman DS (2004) Prognostic relevance of symptoms versus objective evidence of coronary artery disease in diabetic patients. Eur Heart J 25:543-550

16. Zellweger MJ, Lewin HC, Lai S, Dubois EA, Friedman JD, Germano G, Kang X, Sharir T, Berman DS (2001) When to 
stress patients after coronary artery bypass surgery? Risk stratification in patients early and late post-CABG using stress myocardial perfusion SPECT: implications of appropriate clinical strategies. J Am Coll Cardiol 37: 144-152

17. Gibbons RJ, Abrams J, Chatterjee K, Daley J, Deedwania PC, Douglas JS, Ferguson TBJ, Fihn SD, Fraker TDJ, Gardin JM, O'Rourke RA, Pasternak RC, Williams SV, Gibbons RJ, Alpert JS, Antman EM, Hiratzka LF, Fuster V, Faxon DP, Gregoratos G, Jacobs AK, Smith SCJ (2003) ACC/AHA 2002 guideline update for the management of patients with chronic stable angina-summary article: a report of the American College of Cardiology/American Heart Association Task Force on Practice Guidelines (Committee on the Management of Patients With Chronic Stable Angina). Circulation 107:149-158

18. Boden WE, O'Rourke RA, Teo KK, Hartigan PM, Maron DJ, Kostuk WJ, Knudtson M, Dada M, Casperson P, Harris CL, Chaitman BR, Shaw L, Gosselin G, Nawaz S, Title LM, Gau G, Blaustein AS, Booth DC, Bates ER, Spertus JA, Berman DS, Mancini GB, Weintraub WS (2007) Optimal medical therapy with or without PCI for stable coronary disease. N Engl J Med 356:1503-1516

19. Frye RL, August P, Brooks MM, Hardison RM, Kelsey SF, MacGregor JM, Orchard TJ, Chaitman BR, Genuth SM, Goldberg SH, Hlatky MA, Jones TL, Molitch ME, Nesto RW, Sako EY, Sobel BE (2009) A randomized trial of therapies for type 2 diabetes and coronary artery disease. $\mathrm{N}$ Engl J Med 360:2503-2515

20. Hambrecht R, Walther C, Mobius-Winkler S, Gielen S, Linke A, Conradi K, Erbs S, Kluge R, Kendziorra K, Sabri O, Sick P, Schuler G (2004) Percutaneous coronary angioplasty compared with exercise training in patients with stable coronary artery disease: a randomized trial. Circulation 109:1371-1378
21. Henderson RA, Pocock SJ, Clayton TC, Knight R, Fox KA, Julian DG, Chamberlain DA (2003) Seven-year outcome in the RITA-2 trial: coronary angioplasty versus medical therapy. J Am Coll Cardiol 42:1161-1170

22. Hueb WA, Bellotti G, de Oliveira SA, Arie S, de Albuquerque CP, Jatene AD, Pileggi F (1995) The medicine, angioplasty or surgery study (MASS): a prospective, randomized trial of medical therapy, balloon angioplasty or bypass surgery for single proximal left anterior descending artery stenoses. J Am Coll Cardiol 26:1600-1605

23. Pitt B, Waters D, Brown WV, van Boven AJ, Schwartz L, Title LM, Eisenberg D, Shurzinske L, McCormick LS (1999) Aggressive lipid-lowering therapy compared with angioplasty in stable coronary artery disease. Atorvastatin versus revascularization treatment investigators. $\mathrm{N}$ Engl $\mathrm{J}$ Med 341:70-76

24. Weintraub WS, Spertus JA, Kolm P, Maron DJ, Zhang Z, Jurkovitz C, Zhang W, Hartigan PM, Lewis C, Veledar E, Bowen J, Dunbar SB, Deaton C, Kaufman S, O'Rourke RA, Goeree R, Barnett PG, Teo KK, Boden WE, Mancini GB (2008) Effect of PCI on quality of life in patients with stable coronary disease. N Engl J Med 359:677-687

25. Pfisterer ME, Zellweger MJ, Gersh BJ (2010) Management of stable coronary artery disease. Lancet 375:763-772

26. Marie PY, Danchin N, Durand JF, Feldmann L, Grentzinger A, Olivier P, Karcher G, Juilliere Y, Virion JM, Beurrier D et al (1995) Long-term prediction of major ischemic events by exercise thallium-201 single-photon emission computed tomography. Incremental prognostic value compared with clinical, exercise testing, catheterization and radionuclide angiographic data. J Am Coll Cardiol 26:879-886 